\title{
Weaning from mechanical ventilation using tracheostomy cuff deflation and a one-way speaking valve: a historical-cohort series
}

\author{
Stephen Kowalski, MD, FRCPC 10 - Renée El-Gabalawy, MA, PhD - Kandy Macaulay, RRT • \\ Rhonda Thorkelsson, RN, CNCC · Adrian Robertson, MD, FRCPC · Zoheir Bshouty, MD, FRCPC • \\ Linda Girling, BScHons
}

Received: 1 May 2017/Revised: 14 August 2017/Accepted: 31 August 2017 /Published online: 11 September 2017

(C) Canadian Anesthesiologists' Society 2017

\section{To the Editor,}

Overall, $5-15 \%$ of ventilated patients require prolonged mechanical ventilation, most frequently with a tracheostomy. ${ }^{1}$ The optimal method for weaning patients has not been established. Prior research indicates that gradually increasing spontaneous breathing results in faster liberation. ${ }^{2}$ Unfortunately, gradual liberation can take weeks to months, and the use of tracheostomy renders the patient unable to speak. With a speaking valve trial (SVT), however, the tracheostomy cuff is deflated and a one-way valve is attached. Hence, on expiration, air exits the lungs through the vocal cords, enabling vocalization.

We report a historical case series on tracheostomized patients undergoing SVT. The sample consisted of 34 patients admitted to the intermediate intensive care unit during 2013-2014. We conducted a chart review following approval of the University of Manitoba Health Research Board (January, 2017) to identify those with an SVT. Patient profiles were extracted, and data are reported as means (standard deviation).

S. Kowalski, MD, FRCPC $(\bowtie) \cdot$ L. Girling, BScHons Department of Anesthesia \& Perioperative Medicine, Section of Critical Care, University of Manitoba, Winnipeg, MB, Canada e-mail: sekowalski@hsc.mb.ca

R. El-Gabalawy, MA, PhD

Departments of Clinical Health Psychology and Anesthesia \& Perioperative Medicine, University of Manitoba, Winnipeg, MB, Canada

K. Macaulay, RRT $\cdot$ R. Thorkelsson, RN, CNCC

Health Sciences Centre, Winnipeg, MB, Canada

A. Robertson, MD, FRCPC $\cdot$ Z. Bshouty, MD, FRCPC Department of Medicine, Section of Critical Care and Respirology, University of Manitoba, Winnipeg, MB, Canada
Seventeen patients underwent an SVT (Table). Two patients failed the SVT: Patient 1 had repeated aspiration pneumonia, and attempts at cuff deflation were eventually stopped. Patient 2 had poor bulbar function with no control of oral secretions, precluding cuff deflation, which was obvious immediately. The remaining 15 patients' male/ female ratio was $9 / 6$, with a mean (standard deviation [SD]) age of 53 (17) yr All patients had respiratory muscle weakness with a mean (SD) vital capacity of $893(461) \mathrm{mL}$ and a maximum inspiratory force of -20 (11) $\mathrm{cm} \mathrm{H}_{2} \mathrm{O}$ during the initial SVT. SVT patients were ventilated for 94 (44) days and could speak after 71 (39) days of ventilation. Thus, on average, these patients could speak and clearly communicate for $24 \%$ of their time on a ventilator. Patients 3 and 17 were liberated completely from mechanical ventilation within days of initiating the SVT. The mean (SD) duration of the initial SVT was 238 (238) min [range, five minutes to $12 \mathrm{hr}$.

This case series reports the successful use of SVTs in a diverse group of patients who required prolonged mechanical ventilation. There was no protocolized use of the SVTs. The SVTs were initiated based on the attending physician's judgement, as some patients were closer to being liberated than others. The main contraindication was the risk of aspiration.

The major observation among patients with speaking valves was the psychological benefit. Many patients had been unable to speak for months, which can be a great psychological burden to the patients and their families. The paucity of research in this context is surprising given that $90 \%$ of patients who remember their intensive care unit experience indicate being "moderately" to "extremely" bothered by the inability to speak. ${ }^{3,4}$ Tracheostomized patients report symptoms including frustration, fear of safety, sadness, anxiety, and powerlessness related to loss 
Table Course of ventilation in patients with a speaking valve tracheostomy

\begin{tabular}{|c|c|c|c|c|c|}
\hline Patient \# & Diagnosis & $\begin{array}{l}\text { Intubation to } \\
\text { speaking }^{\text {a }} \text { (days) }\end{array}$ & $\begin{array}{l}\text { Speaking to } \\
\text { liberation (days) }\end{array}$ & $\begin{array}{l}\text { Intubation to } \\
\text { liberation }^{\text {b }} \text { (days) }\end{array}$ & $\begin{array}{l}\text { Duration of initial } \\
\text { SVT (min) }\end{array}$ \\
\hline 1 & Stroke & 89 & NA & 246 & 60 \\
\hline 2 & MVA-SCI & 45 & NA & 233 & 2 \\
\hline 3 & $\mathrm{GBS}^{+}$ & 65 & 26 & 91 & 480 \\
\hline 4 & Pancreatitis & 140 & 3 & 143 & 240 \\
\hline 5 & Pancreatitis & 62 & 12 & 74 & 60 \\
\hline 6 & Lung transplant & 52 & 45 & 97 & 360 \\
\hline 7 & $\mathrm{MVA}^{++}$ & 168 & 39 & 207 & 240 \\
\hline 8 & $\mathrm{GBS}^{+}$ & 53 & 16 & 69 & 60 \\
\hline 9 & Colon resection & 19 & 13 & 32 & 720 \\
\hline 10 & MVA-SCI $^{+++}$ & 97 & 15 & 112 & 30 \\
\hline 11 & Lower GI bleed & 83 & 21 & 104 & 60 \\
\hline 12 & Lung transplant & 33 & 8 & 41 & 720 \\
\hline 13 & $\mathrm{MVA}^{++}$ & 39 & 22 & 61 & 240 \\
\hline 14 & Stab to aorta & 72 & 38 & 133 & 5 \\
\hline 15 & Myasthenia gravis & 72 & 30 & 102 & 240 \\
\hline 16 & Aspiration pneumonia & 51 & 28 & 79 & 60 \\
\hline 17 & MVA-SCI ${ }^{+++}$ & 59 & 3 & 62 & 60 \\
\hline $\operatorname{Mean}(\mathrm{SD})^{\mathrm{c}}$ & & $71(39)$ & $21(13)$ & $94(44)$ & $238(238)$ \\
\hline
\end{tabular}

\footnotetext{
${ }^{a}$ Intubation to speaking: time from initial intubation until the tracheostomy cuff was deflated, with a speaking valve in place, for two consecutive days

${ }^{b}$ Intubation to liberation: time from the initial intubation until the patient was breathing unassisted for 48 consecutive hours

c Values for patients 3-17 only

GBS = Guillain-Barre syndrome; MVA = motor vehicle accident SCI = spinal cord injury. SVT = speaking valve trial
}

of voice. Patients view the inability to speak as worse than the pain and discomfort associated with the tracheostomy itself. Patients have described the meaning of their nonvocal experience as: “...being trapped in a silent world makes me feel frustrated and incomplete." 5

The inability to speak also has healthcare consequences as it has been found to be associated with patient disengagement in health care and noncompliance with the care plan, which may extend the length of stay and could have significant, negative long-term health sequelae. $^{4}$

The purpose of this case series was to shed light on the utility of SVT to facilitate further research on this important and overlooked intervention. Randomized controlled trials should seek to understand the psychological and health benefits of SVT in patients on prolonged mechanical ventilation with tracheostomy. Identified health benefits may significantly affect the standard of care of tracheostomized patients with earlier initiation of cuff deflation enabling speech. The Roman philosopher Publius Syrius stated, "Speech is a mirror of the soul; as a man speaks, so is he."
Acknowledgements This study was supported by a grant from the Anesthesia Oversight Committee, Department of Anesthesia and Perioperative Medicine, University of Manitoba.

Conflicts of interest None declared.

Editorial Responsiblity This submission was handled by Dr. Gregory L. Bryson, Deputy Editor-in-Chief, Canadian Journal of Anesthesia.

\section{References}

1. Martin AD, Smith $B K$, Gabrielli A. Mechanical ventilation, diaphragm weakness and weaning: a rehabilitation perspective. Respir Physiol Neurobiol 2013; 189: 377-83.

2. Jubran A, Grant BJ, Duffner LA, et al. Effect of pressure support vs unassisted breathing through a tracheostomy collar on weaning duration in patients requiring prolonged mechanical ventilation a randomized trial. JAMA 2013; 309: 671-7.

3. Khalaila $R$, Zbidat W, Anwar K, Bayya A, Linton DM, Sviri S. Communication difficulties and psychoemotional distress in patients receiving mechanical ventilation. Am J Crit Care 2011; 20: $470-9$ 
4. Patak L, Gawlinski A, Fung NI, Doering L, Berg J. Patients' reports of health care practitioner interventions that are related to communication during mechanical ventilation. Heart Lung 2004; 33: $308-20$.
5. Carroll SM. Silent, slow lifeworld: the communication experience of nonvocal ventilated patients. Qual Health Res 2007; 17: 116577. 